\title{
BIBECHANA
}

A Multidisciplinary Journal of Science, Technology and Mathematics ISSN 2091-0762 (Print), 2382-5340 (Online)

Journal homepage: http://nepjol.info/index.php/BIBECHANA

Publisher: Research Council of Science and Technology, Biratnagar, Nepal

\section{Perception of fish farmers to wildlife predator attacks of fish ponds in Borgu Local Government Area of Niger State, Nigeria}

\author{
K.M. Adelakun", A. J. Adeola, S. M. Ayeni, K. Bakare \\ Federal College of Wildlife Management, P.M.B. 268, New Bussa, Nigeria \\ "E-mail: adelakunkehinde@gmail.com \\ Article history: Received 11 July, 2015; Accepted 10 August, 2015 \\ DOI: http://dx.doi.org/10.3126/bibechana.v13i0.13344
}

\section{Abstract}

The study assessed the perception of fish farmers to wildlife predators' attack of fish ponds in Borgu Local Government area of Niger state, Nigeria. The study covered three wards; Bussa, Karabonde and Rafi which were purposively sampled. Questionnaire, personal interview and physical observation were employed to collect necessary data. A face to face questionnaire survey was carried out on a total of thirty-two (32) fish farmers and pond managers to elicit information on extent of predator's activities by wildlife, and frequency of occurrence and period or season of predation. The result revealed that predation occurred both day and night. Most respondents $(65.63 \%)$ attested to the predator attack in the fish farm. The most preferred prey size appeared to be fish fingerlings which were consumed wholly. Five (5) wildlife species include frog (Rana sp) 16.66\%, wildcat (Felis silvestris) 8.3\%, water snake (Grayia smithii) $11.66 \%$, monitor lizard (Varanus niloticus) and birds like kingfisher( Alcedo sp) $26.66 \%$ were identified as the predators of fish. From the wildlife species identified, birds mostly attack fish in ponds in the study area. Wildlife predators including reptiles and amphibians are some of the numerous challenges to culture fisheries in the study area. However, the preventive measures and controls of wild animals attacked fish in farms are netting (59.38\%) which is the best method to prevent predators from fish ponds, fencing $(28.13 \%)$ and security guards $(12.50 \%)$. In control measure, $68.75 \%$ confirmed that the physical method usually works better than biological and chemical control measures. Hence, its adoption for the management of the pest and predators is essential for sustainable culture fisheries in the study area.

CRCOST: All rights reserved.

Keywords: Fisheries; perception, predator; ponds, prey; wildlife. 


\section{Introduction}

Wildlife species prey on fish ponds and the predators are significant causes of reduction in fish population in ponds, resulting to low output [1]. Wildlife occurring at aquaculture sites can ignite conflicts over resources managed by humans [2].

Fish predators are attracted to farm ponds by abundant food supplies and specific habitats hence many generate human-wildlife conflicts by causing stock losses and physical destruction at aquaculture facilities [3, 4]. Predation describes a biological interaction, where a predator feed on its prey [5]. Predators may or may not kill their prey prior to feeding on them, but the act of predation often results in the death of its prey and the eventual absorption of the prey's tissue through consumption [6].

The act of predation can be broken down into a maximum of three (3) stages: Detection of prey, attack or capture and finally consumption. The relationship between predator and prey is one which is typically beneficial to the predator, detrimental to the prey species. Sometime however, predation has indirect benefits to the prey species though the individuals preyed upon do not benefit. This means that, at each applicable stage predator and prey species are in an evolutionary superiority to maximize their respective abilities to obtain food or avoid being eaten [7].

Predation eliminates a prey species and many studies have shown predations to be an important factor in maintaining species diversity and ecological balance in a community [8].

Although predation may not always limit prey population, the availability of prey constitutes a major component of the carrying capacity of predator population; this is evident in relatively simple situations, such as when bloom of phytoplankton resulting from an upwelling of nutrients due to ocean currents and this is followed by a corresponding increase in zooplankton [8].

Culture fisheries like every other agricultural practice encounter problems; this destroy fish or hinder the production of target fish species [9], these predators can be grouped into birds, mammals, amphibian and reptiles which can retards fish product.

A true predator can commonly be known as one which kills and eats another organism. Whereas other types of predators all harm their prey in some way or certainly kills them e.g Hippopotamus. Predators may hunt actively for prey, or sit and wait for prey to approach within striking distance, as in ambush predators. Some predators kill large prey and dismember or chew it prior to eating it, such as a Alligator or a human; others may eat their (usually much smaller) prey whole, as does a bottlenose dolphin swallowing a fish, or a snake, duck or stork swallowing a frog. Some animals that kill both large and small prey for their size may do either depending upon the circumstances; either would devour a large insect whole but dismember a fish. Some predation entails venom which subdues a prey creature before the predator ingests the prey by killing, which 
the box jellyfish does, or disabling it, found in the behaviour of the cone shell. In some cases, the venom, as in rattlesnakes contributes to the digestion of the prey item even before the predator begins eating. In other cases, the prey organism may die in the mouth or digestive system of the predator.

Increases in some wildlife populations and their spread into human -dominated landscapes are a growing concern $[10 ; 11]$. Wildlife predation on fish ponds have serious consequences both for the profitability of aquaculture enterprise, due to loss of production and costs of implementing damage control or prevention methods [10] and for wildlife population, due to the cumulative adverse impact of human-mediated mortality of wildlife (Kloskowski, 2010).

Monitoring wildlife predators on fish farm may yield a substantial amount of population data on wildlife interacting with fisheries which may be especially valuable in the area of animal conservation and economic interest. Therefore, this work assessed the occurrence, distribution and perception of wildlife species that may adversely affect fisheries yield in the context of the potential impact on pond culture in the study area.

\section{Materials and method}

\section{Study area}

Borgu Local Government Area lies between Latitude $90^{\circ} \mathrm{N}$ and $11^{\circ} \mathrm{N}$ and longitude $2^{\circ} \mathrm{E}$ and $4^{0} \mathrm{E}$, covering a land mass of about $16,200 \mathrm{~km}$ providing both natural and acquired materials of attraction to business and economic activities [12]. A reconnaissance survey of major pond sites within purposively selected wards of Borgu Local Government area in Niger state was carried out in September, 2012 to determine our sample size for data collection in October, 2012 to April 2013.Sites were selected based on strategic and level of fish culture production i.e grow-out fish farmer were considered.

\section{Methodology Study population}

Borgu Local Government Area consists of ten (10) political wards namely: Babanna, Bussa, Duga, Kabe, Karabonde, Konkoso, Malale, Rafi, Shagunu and Wawa. This survey cut across fish farmer who have fish farms and direct link of responsibility to the issue being investigated in three major wards of Bussa, karabonde, and Rafi because preliminary survey has shown that the wards have considerable number of fish farms (at least 4)

\section{Sample size and sample techniques}

From the reconnaissance survey of the study area, population census of the farms comprising the study populations are:

Bussa ward-30 fish farms; Karabonde ward (including Monai)-6 fish farms; Rafi ward- 6 fish farms

$\mathrm{N}$ [sample population] $=42$; Simple random sampling were used in order to select between 75 to $100 \%$ sample size from each selected ward to have thirty - two $(32)$ respondents i.e $(20+6+6)=32 ; n=32(85.7 \%)$ 
where $\mathrm{n}=$ Sample size.

\section{Data collection}

Data were collected from two main sources, on site data collection and social survey through structured questionnaire which was administered to fish farmers and fish pond managers (Onadeko et al., 2000). Each pond site was visited and wildlife predators activities were observed around their boundary and within pond. Physical appearance and behavioural activity pattern of various kinds of animals visiting the ponds were noted. Observations were made at different periods of the day (morning, afternoon and evening). Physical examination was conducted where fish carcasses were found.

Face to face questionnaire survey were administered to a total of thirty -two (32) fish farmers and pond managers to elicit information on extent of predators activities by wildlife, and include frequency of occurrence of predators and time of season.

\section{Data analysis}

All data collected were interpreted using descriptive statistics of frequency tables and simple percentage.

\section{Results}

Table 1: Demographic characteristic of respondents.

\begin{tabular}{lll} 
Variables & Frequency & Percentage (\%) \\
\cline { 2 - 3 } Age & 15 & 46.88 \\
$20-30$ & 12 & 37.50 \\
$31-40$ & 5 & 15.63 \\
41 above & & \\
Sex & 31 & 98.88 \\
Male & 1 & 3.13 \\
Female & & \\
Marital status & 19 & 59.38 \\
Single & 13 & 40.63 \\
Married & & \\
Occupation & 21 & 65.63 \\
Fish farming & 7 & 21.88 \\
Civil servant & 4 & 12.5 \\
Student & & \\
Educational qualification & - & - \\
Primary & 6 & 18.75 \\
Secondary & 25 & 78.13 \\
Tertiary & 1 & 3.13 \\
Others[informal] & & \\
& &
\end{tabular}

Table 1 revealed the demographic characteristic of respondents. Majority age of respondent is within the 20 and 30 (46.88\%), while the least respondents are aged 41 and above. However, most respondents are 
male (96.88\%), single respondents are 59.39\% in comparison to $40.63 \%$ married. Major occupation of the respondents is fish farming $(65.63 \%)$, while $21.88 \%$ and $12.5 \%$ are civil servants and students respectively. Respondents with formal education are (78.13\%).

Table 2: Management practice of respondents.

\begin{tabular}{|c|c|c|}
\hline Variables & Frequency & Percenta \\
\hline $\begin{array}{ll}\text { Culture } & \text { system } \\
\text { methods) } & \end{array}$ & (rearing & \\
\hline Extensive & 5 & 15.63 \\
\hline Intensive & 12 & 37.50 \\
\hline Semi intensive & 15 & 46.88 \\
\hline $\begin{array}{l}\text { Scale of operation } \\
\text { production capacity) }\end{array}$ & (Based on & \\
\hline Commercial & 30 & 68.18 \\
\hline Subsistence & 14 & 31.81 \\
\hline Both & 1 & 3.13 \\
\hline \multicolumn{3}{|l|}{ Species of fish culture } \\
\hline Catfish & 29 & 90.63 \\
\hline Tilapia & 2 & 6.25 \\
\hline Both & 1 & 3.13 \\
\hline \multicolumn{3}{|l|}{ Sorting of fish stock } \\
\hline Yes & 27 & 84,38 \\
\hline No & 2 & 6.25 \\
\hline No response & 3 & 9.38 \\
\hline
\end{tabular}

From table 2, semi-intensive farming is mostly practiced in the study area (46.88\%) while extensive was least practiced (15.63\%). However, in fish farming, respondents that based production on commercial level are more (68.18\%) when compared to subsistence farming (31.81\%). Similarly, the species of fish culture is mostly catfish (90.63\%). 87.57\% do stock taking/counting of fish while those that do not and no response were $6.25 \%$ and $3.13 \%$ respectively. Result also show that $84.38 \%$ of the respondents do sort fish stock while only $6.25 \%$ do not, though $34.38 \%$ do the sorting monthly while only $3.13 \%$ sort occasionally.

Prevalent wildlife attacking fish farms in the study area

Figure 1 revealed that monitor lizard mostly attack fish in the pond in the study area compare to other species of animals. 


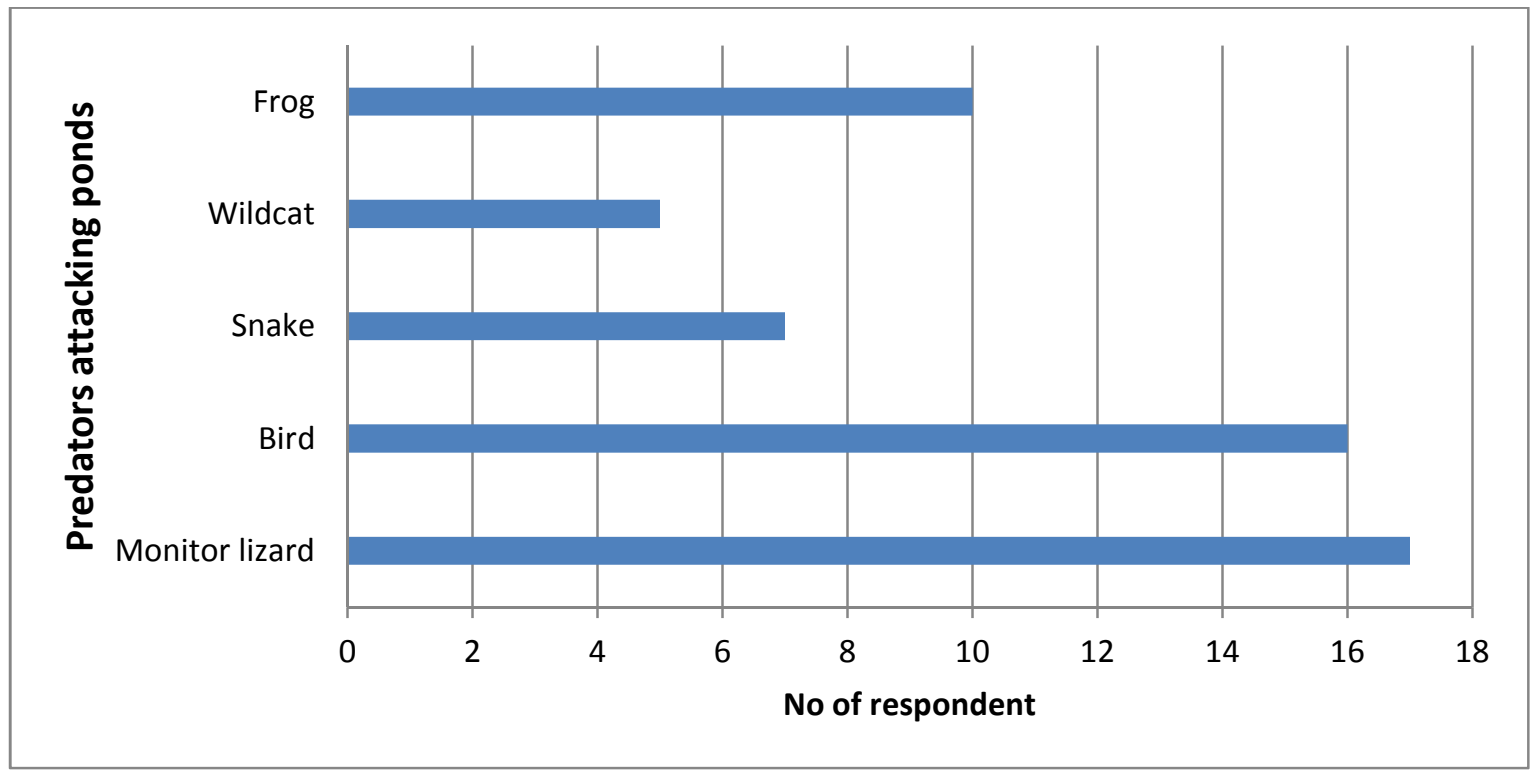

Fig. 1: Response to pond predators prevalent in the study area.

Table 3: Wildlife predation perception of respondents.

Oariables

Yes

Frequency

Percentage

No

21

65.63

No response

10

31.25

\section{Respondent preference for predator attack}

Yes

No

30

93.75

No response

2

6.26

Daily time of attack

Morning

4

12.5

Afternoon

Night

-

7

21.88

Both day and night

65.63

Frequency of the attack

Occasionally

28.13

Weekly

6.25

Season of attack

Dry season

50.0

Rainy season

28.13

All year round

Stage of fish predators mostly attack

Fry

Fingerling

9.38

Juvenile

19

59.38

Grow-out 
From table 3,65.63\% admitted to predator attack on their pond while 31.25\% did not. Most respondents (93.74\%) do not wish for predator attack, while $6.26 \%$ did not respond to the question. The result further revealed that, predator mostly attack pond during day and night (65.63\%). 50\% of the respondents reported that predatory activities are more pronounced during the dry season than in rainy season $(28.13 \%)$ while $21.88 \%$ that it was all year round. It was also reported that, predator mostly attack fish fingerling (59.38\%) compare to other growing stages of fish.

Table 4: Wildlife Attack Prevention and Controls Measures in Fish Farms.

\begin{tabular}{|c|c|c|}
\hline Variables & Frequency & Percentage \\
\hline \multicolumn{3}{|l|}{ Preventive measures } \\
\hline Fencing & 9 & 28.13 \\
\hline Security & 4 & 12.5 \\
\hline Covering pond with net & 19 & 59.38 \\
\hline \multicolumn{3}{|l|}{ Control measures } \\
\hline Chemical (e.g Lime) & 1 & 3.13 \\
\hline $\begin{array}{l}\text { Biological (e.g use of hunting } \\
\text { animals like trained dog) }\end{array}$ & 9 & 28.13 \\
\hline Physical & 22 & 68.5 \\
\hline
\end{tabular}

From table 4, most respondents (59.38\%) reported that netting is the best method to prevent predator from fish pond than fencing (28.13\%) and use of security personnel (12.5\%). 68.75\% confirmed that they used physical method, while $28.13 \%$ and $3.13 \%$ preferred biological and chemical methods respectively.

\section{Discussion}

From the finding it is strongly agreed that, occurrence, distribution and perceptions of wildlife species at pond fisheries were not desirable probably due to the fact it could leads to loss of fish stocked. This has been reported by Kloskowski [2] that serious damage of pond fisheries is caused by wildlife in eastern Poland. The present results show that presence of birds and reptiles in pond could pose a serious economic problem to fish farmer. These wildlife species observed in the study area had earlier been reported as fish predators by Bellairs, [3]; Brown, [14]; Landan, [15]. The high response to the existence of birds' predator in this study area is in conformity with Shitote et al., [16] who reported birds as the highest predator of fish in Western Kenya. Wild animals dominated the aquaculture damage; they were widely reported and believed to be responsible for severe stock losses at over a half the sites where they 
were observed. The present survey shows that monitoring fish farms may yield a substantial amount of data on wildlife interacting with fisheries. This may be especially valuable in the case of mammals, for which monitoring schemes are less developed than those for birds [17]. Wildlife observations from fish farms may be useful for atlas data and assessment of population dynamics. Therefore, confirmation on the regular occurrence of these species at fish farms should justify the preventive measure and control measure of wildlife attack in fish farms to avert human-wildlife conflict.

A related problem is adequate assistance in managing wildlife damage at fish farms suffering costs from multiple problem species. Financial burdens on this group of farms may be particularly heavy, due to the different types of production losses to species with differing impact on farm resources and because protective measures against different groups of nuisance species require greater expenditures.

\section{Conclusion}

Farmers that engaged vigorously on this fish farming business are often faced with various challenges among which are the fish predators; which could drastically affected fish production in recent years. Wildlife predators which include aquatic birds, reptiles, mammal (including man as poacher) and amphibians such as frog are some of the challenges to culture fisheries in the study area. These predators destroy fish or hinder the production of target fish species. Hence, the management of the predators is essential for the sustaining culture fisheries as wildlife predatory activities may constitute an economic problem to fish pond management in the study area. Uncontrolled predation on fish is inimical to the survival of fish culture business. It is of great importance therefore, to keep fish predation at its lowest.

\section{References}

[1] S.A Onadeko, G.N.O.Ezeri and A.L.A. Shotuyo, Aquafield, 1 (1) (2000) 45-52.

[2] J. Kloskowski, European Journal of Wildlife Research, 57(2) (2010)295-304.

[3] R. Billard (eds.), Carp: Biology and Culture. Springer, Berlin, 1999.

[4] K. Dobrowolski, (eds.), Environmental-Economic Evaluation of Fish Ponds in Poland. IUCN, Warszawa, 1995.

[5] M. Begon, C. Townsend and J. Harper, Ecology: Individuals, populations and communities (Third edition) Blackwell Science, London, 1996.

[6] Encyclopedia Britannica, Predation, www.britannica.com: predation, 2013.

[7] M. Homing and J.E. Mellish, Plots ONE 7 (1) (2012).

[8] H. Curtis, Biology of fishes (2nd eds) John Wiley and sons, Inc (Publ), 1993 pp 5-11.

[9] Niger Delta Environmental Survey (NDES), Final Report of Phase 1, Vol. 1, 1997.

[10] Z. Adámek, H. Klinger, E. Staub, Suppl. Ric. Biol. Selvag, 26 (1997) 347-353.

[11] A. Kranz, Mammalia, 64 (2000) $357-368$.

[12] F.O. Amobode, Influence of human activities on the conservation of flora and fauna resources of Kainji Lake National Park, 1989 pp 245-256.

[13] A. A. Bellairs, The Encyclopedia of wildlife introduction to Reptiles and Tortoise: Alligators and crocodiles, Lizards and snakes. Longman London, 1974 (Publl.) pp 980. 
K.M. Adelakun et al. / BIBECHANA 13 (2016) 29-37: RCOST p.37 (Online Publication: Dec., 2015)

[14] L.H. Brown, Birds of African Waterside. Macmillan Company, London, New York. 1979 (Publl) p 230.

[15] M. Landan Introduction to agricultural john Wiley and sons, Inc., 1992 (Publ) p127.

[16] Z. Shitote, J. Wakhungu, and S. China, Challenges facing fish farming development in Western Kenya. Greener Journal of Agricultural Sciences, 3(5) (2013) 305-311.

[17] J. E. Battersby and J.D. Greenwood Mammal Rev., 34 (2004) 3-29. 